\title{
evolução do vinho espumante da serra gaúcha*
}

\author{
Marcos do Couto Bezerra Cavalcanti \\ Professor do Programa de Engenharia de Produção da Coppe/UFRJ; PhD pela Université de \\ Paris XI (Paris-Sud); membro do Board do New Club of Paris.
}

Claudia Maria de Holanda $\star \star$

Mestra em Engenharia de Produção pela Coppe/UFRJ; graduada em Comunicação Social pela Universidade Federal de Pernambuco.

\section{RESUMO}

Como o Brasil, um país com pouca tradição no vinho, tem demonstrado evolução justamente com o produto mais sofisticado dessa indústria, o vinho espumante? Este artigo descreve os processos que reinventaram o espumante brasileiro produzido no sul do país (Serra Gaúcha), articulando os modelos teóricos da Gestão do Conhecimento e da Teoria das Convenções.

Embora seja um produto industrial, o vinho não é um produto que obedeça a regras pré-estabelecidas de elaboração. Clima e tecnologia adequados, boa matéria-prima (uvas) e equipamento apropriado são parte do esforço, mas não são suficientes para produzir vinhos de boa qualidade sem a interferência do homem, com seu conhecimento, sensibilidade e intuição. Na produção e consumo de vinho existem fatores imateriais e intangíveis, o que nos levou a pesquisar autores relacionados à teoria de Gestão do Conhecimento.

\begin{abstract}
How Brazil, a country with little tradition in wine, has been demonstrating evolution precisely with the more sophisticated product of this industry, the sparkling wine? This article describes the processes that reinvented the Brazilian sparkling wine produced in the south of the country (Serra Gaúcha) based on two theories: Conventions and Knowledge Management.

Although it is an industrial product, wine is not a product that obeys pre-established rules of elaboration. Technology, suitable climate, good raw material (grapes) and appropriate equipment are part of the effort, but they are not enough to produce good quality wines without the interference of man, his knowledge, intuition and sensitivity. We understand that in a bottle of wine, there are explicit and tacit knowledge. In the production and consumption of wine, there are immaterial and intangible factors, which led us to search authors related to the theory of Knowledge Management.
\end{abstract}

* Submetido: junho, 2012; aceito: setembro, 2012.

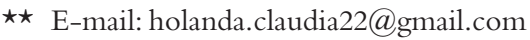


A combinação de cultura, tecnologia e knowhow local está presente na ideia de terroir, conceito abordado pela Teoria das Convenções. Esta teoria tem uma relação intrínseca com o agronegócio e caracteriza-se por uma orientação fortemente interdisciplinar que procura explicar a noção de qualidade endogenamente, considerando a interação dos atores envolvidos no processo.

Este artigo passa pela cadeia de produção de vinho espumante e investiga, na região escolhida, a relação entre tecnologia, conhecimento, condições naturais, profissionais envolvidos, o espumante gerado e seu consumo.

Palavras-chave: Espumante. Serra Gaúcha. Teoria das Convenções. Gestão do Conhecimento. Indústria vinícola brasileira.
The combination of technology, culture and local know-how is present in the idea of terroir, which is well studied in the Theory of the Conventions. This theory has an intrinsic relationship with agribusiness and explains the notion of quality endogenously, considering the interaction of actors involved in the process.

This article goes through the sparkling wine production chain and investigates, in the chosen region, the relationship between technology, knowledge, and characteristics of soil, grapes, professionals, the sparkling wine generated and its consumption.

Key words: sparkling wine, Serra Gaúcha, Conventions Theory; Management Knowledge, Brazilian wine industry

\section{Introdução}

O vinho espumante produzido no Brasil vem se destacando em concursos no exterior e, também, ganhando espaço no mercado interno. Esse produto conquistou centenas de medalhas e distinções em concursos internacionais, alguns realizados inclusive na França, berço do Champagne. Tal reconhecimento leva a pensar que o Brasil possui vantagens competitivas para a produção de espumantes e que também houve uma melhora expressiva na qualidade dessa bebida, posto que sua produção no estado do Rio Grande do Sul ocorre desde a segunda década do século XX.

Mas somente a partir dos anos 2000, praticamente 100 anos depois, começou a ser prestigiado nessa escala. No entanto, embora o espumante brasileiro venha gradualmente ganhando notoriedade internacional, a exportação dessa bebida é insignificante. Sua qualidade vem sendo observada em circuitos de especialistas, mas ainda sem força para competir com espumantes mais tradicionais, como o champagne, o cava espanhol e o prosecco italiano.

Por outro lado, a partir de 2000 o consumo interno de vinho espumante apresenta crescimento. Como veremos a frente, praticamente toda produção é consumida dentro do país. O vinho já é a segunda bebida na preferência nacional. Segundo dados do I Levantamento Nacional

\section{I Marcos do Couto Bezerra Cavalcanti - Claudia Maria de Holanda}


Sobre os Padrões de Consumo de Álcool na População Brasileira (2007), feito ao longo de novembro de 2005 a abril de 2006, de todas as doses anuais consumidas por brasileiros adultos dos dois gêneros, de qualquer idade e região do país, em torno de $61 \%$ são de cerveja ou chope e $25 \%$ de vinho (Uniad, 2007: 37-38). Para a composição do estudo citado foram entrevistadas 3.007 pessoas, sendo 2.346 adultas com mais de 18 anos e 661 adolescentes entre 14 e 17 anos, em 143 municípios brasileiros, de norte a sul do País.

Segundo Miele et al. (2007:227), “o mercado nacional é considerado pequeno, com um baixo consumo per capita de vinho, menos de 2 litros por pessoa por ano. A classificação determinada pela legislação brasileira permite a identificação de mais de 25 produtos derivados da uva e do vinho (de vinho espumante a vinagre), porém a produção de produtos de baixo valor predomina, como vinho de mesa e suco de uva concentrado". É, então, no mínimo inusitado que o Brasil, país sem tradição vinícola, passe a ser reconhecido no mundo do vinho justamente com o produto mais sofisticado dessa indústria, o espumante.

Além dos métodos de produção, matéria-prima e observação do consumo, pretende-se, neste artigo, abordar o aspecto imaterial existente na elaboração dessa bebida. $\mathrm{O}$ vinho fino tranquilo ${ }^{1}$ - ou espumante -, mesmo sendo industrializado, não é um produto comum, que obedeça, simplesmente, a regras de maximização da produção, ou que possua uma receita única para ser elaborado. No universo do vinho, mistura-se o tangível e o intangível, tanto na produção como no consumo. Em uma garrafa de vinho há muito conhecimento tácito e explícito.

O vinho não é uma mercadoria comum. Vinhos de qualidade devem ser oriundos de uvas cultivadas em áreas geográficas específicas, e sua elaboração, obedecer a regras mais complexas do que a simples minimização de custos de produção. Com efeito, a qualidade final dos vinhos de uma região vinícola não é puramente o resultado da somatória de fatores naturais, mas sim, de uma combinação de cultura, talentos e expertises múltiplas e complexas. (RÉVILLION et al., 2007: 177).

Para Roese (2008: 71), “a globalização do mercado vinícola não se dá, portanto, pela expansão pura e simples do consumo e da oferta, mas

1 Vinho tranquilo é o vinho que não possui gás carbônico. 
pela criação de uma demanda global por produtos de alta qualidade, com alto valor agregado e com características bem específicas, visando um mercado diferenciado. $O$ fascínio que essa bebida exerce sobre os consumidores e a mística que envolve seus produtores e as regiões onde o vinho é produzido e engarrafado pode explicar, em parte, esse fenômeno".

No Brasil, existem produções vinícolas em Santa Catarina, São Paulo, Minas Gerais, Paraná,Vale do São Francisco (na divisa entre Pernambuco e Bahia) e no Rio Grande do Sul, estado que detém mais de $90 \%$ da produção. A região da Serra Gaúcha, no Nordeste do Rio Grande do Sul, é onde mais se produz espumantes no Brasil - e também onde estão os rótulos mais premiados. Por tais fatores, este estudo se concentra na análise dessa localidade.

Como na produção e no consumo de vinho há fatores imateriais e intangíveis, consideramos viável e coerente compulsar autores relacionados a teorias da Gestão do Conhecimento para analisar as transformações da indústria. A Teoria das Convenções nos apoia na interpretação da mudança de percepção em relação à qualidade do espumante brasileiro por parte do consumidor.

Os vinhos espumantes brasileiros representam a maior história de sucesso dos esforços realizados na Serra Gaúcha. De acordo com a Associação Brasileira de Enologia (ABE), entidade responsável por inscrever as amostras de vinhos brasileiros em concursos, de 2002 a 2011, o espumante já acumulou mais de mil medalhas em competições internacionais ${ }^{2}$. Ressaltamos, no entanto, que dessa extensa lista, há concursos pouco expressivos, realizados em países com quase nenhuma tradição vinícola. Feita essa ressalva, ainda assim pode-se afirmar que, dessa numerosa quantidade de medalhas, há premiações de fato importantes, como as recebidas nos concursos Effervecents du Monde, na França, e o International Wine Challenger (IWC), em Londres, entre outros.

Décadas, e até mesmo séculos, são necessários para que um local passe a ser reconhecido como produtor de vinho e obter o ganho de imagem que essa deferência pode dar. A reputação de um país como produtor de vinho não se constrói rapidamente, e é certo que o Brasil, mesmo com toda euforia em torno de seus espumantes, ainda não atingiu esse estágio.

2 Uma tabela com esse estudo foi gentilmente enviada pela ABE.

8 I Marcos do Couto Bezerra Cavalcanti - Claudia Maria de Holanda 
O País ainda é visto muito mais como um mercado consumidor. No entanto, os espumantes apresentam, atualmente, um grande potencial de melhoria e crescimento de vitivinicultura brasileira. As condições climáticas da Serra Gaúcha - que levam a vinhos de elevada acidez e baixo teor alcoólico - não representam impedimento para os espumantes, mas um trunfo a ser valorizado, justamente porque a acidez promove frescor, vivacidade e equilíbrio a essa bebida após a segunda fermentação.

No Sul, as terras para a produção de vinhos já atingiram alto valor de mercado e estão ocupadas por mais de 600 empresas produtoras de vinho em todo o estado. No entanto, a história do espumante nacional ainda é uma questão em aberto. Segundo Cabral (2007), não apenas os espumantes, mas o estudo do vinho brasileiro, ainda não está completamente delineado.

Salvo os trabalhos existentes sobre vinho no Rio Grande do Sul, nenhum historiador pátrio ou brasilianista trabalhou especificamente sobre quando, como, por que e até o onde o brasileiro consumiu, produziu, comercializou vinho em cinco séculos de história. (CABRAL, 2007: 8).

\section{Uma revisão de literatura}

Nas bases científicas, ainda é recente e escassa a literatura sobre os espumantes nacionais com interesse na análise de aspectos históricos e produtivos. Os artigos se direcionam muito mais para características sensoriais, químicas e biológicas da bebida, sem analisar os processos de mudança do ponto de vista gerencial, aspectos produtivos e tecnológicos, que são os assuntos que compõem o enfoque deste texto.

A seguir, são delineados os modelos teóricos que esteiam essa investigação, a saber: a teoria das convenções, que fornece caminhos a respeito da percepção da qualidade de produtos agrícolas; e a gestão do conhecimento, para análise dos processos de mudança na indústria vinícola.

\section{Teoria das convenções}

As primeiras acepções da Teoria das Convenções encontram-se em artigos publicados na Revue Économique (1989) e, posteriormente, na obra 
De la justification: les économies de la grandeur, do sociólogo Luc Boltanski e do economista Laurent Thévenot, publicada em 1991. Juntos, idealizaram uma nova sociologia econômica que se contrapunha ao modelo econômico neoclássico - que considera o capital, o trabalho e a terra como principais fatores de produção.

Uma convenção de qualidade consiste em um modo de coordenação dos comportamentos dos agentes no mercado. Para a teoria das Convenções, a qualidade é o resultado de mecanismos de interação entre os indivíduos e os objetos em causa, sendo, por isso, uma construção social, razão pela qual existem diversas formas de construção da qualidade (DIAS, 2005). Clovis Dorigon, em sua tese de doutorado sobre produtos coloniais de Santa Catarina, explica que

A teoria das convenções desenvolveu-se em torno de um tema tradicional, a singularidade da mercadoria 'trabalho', abordado também pela nova microeconomia, sob a forma de 'contrato incompleto', desenvolvendo uma análise das regras, normas e convenções que subscreveram a relação salarial (DORIGON, 2008: 68).

Dorigon (2008:70-71) argumenta, ainda, “que as regras são representações dinâmicas de negociação e como tal dependem da existência de atributos comuns entre os atores envolvidos". O professor Wilkinson (1999: 65) afirma que “enquanto o fordismo se baseava na 'qualificação' do trabalho para a maior quantificação da produção, a atual dinâmica econômica baseia-se precisamente na qualificação do produto, capturada pela atual obsessão com a qualidade".

Enquanto a corrente neoclássica tenderia a continuar a ver a questão como o estabelecimento exógeno de novas regras, a Teoria das Convenções procura explicar, de uma forma endógena, o aparecimento das bases objetivas para a definição da qualidade, mediante a interação dos atores intervenientes no processo. A definição da qualidade torna-se um processo interno. Daí, uma convenção de qualidade não é apenas um conjunto de regras negociadas entre os atores, mas também um processo de coordenação das ações individuais que tornam os processos coerentes dentro de um mesmo "mundo de produção" (SIMÕES, 2002).

Há pontos inconciliáveis entre a teoria neoclássica e a teoria das convenções: 
A economia neoclássica, ou o que os franceses chamam de teoria 'padrão', não tem utilidade para a colaboração interdisciplinar, uma vez que, por definição, nenhum autor pode influenciar o comportamento do outro, e as preferências e a tecnologia representam estados do mundo exógenos. Todavia, na base comum que identificamos, a atividade econômica é socialmente construída e mantida historicamente determinada por ação coletiva e individual expressa através de organizações e instituições. (WILKINSON, 1999: 66)

A convenção não existe por si só, manifesta-se na ação dos indivíduos (DIAS, 2005: 16). Para dar conta da diversidade de formas de coordenação, a teoria das convenções propõe um conceito para descrever a pluralidade dos modos de coordenação dos agentes em um universo de incerteza. Para caracterizar o universo das relações, Boltanski e Thévenot (1991: 107) criaram a noção de grandezas ou cidades puras e teóricas. São elas: 1) cidade da inspiração; 2) cidade doméstica; 3) cidade da opinião; 4) cidade cívica; 5) cidade industrial; e 6) cidade mercantil. Cada uma delas possui princípios ou estados de natureza relacionados. São eles: princípio do bem comum, dignidade comum, humanidade comum, da diferença, da existência de ordens de grandeza e da fórmula de investimento.

Associando as cidades com seus princípios ou estados de natureza são construídos seis mundos, que justificam e explicam os modos de ação.

Supomos que esses seis mundos são suficientes para descrever justificativas na maioria das situações comuns. Mas claro que esse número não é mágico. Estes mundos são construções históricas e alguns deles são menos capazes de fundamentar as justificativas das pessoas, enquanto outros emergem. (BOLTANSKI; THÉVENOT, 1999: 369).

Como explicam Boltanski e Thévenot (1999), os mundos são:

1 - Mundo da inspiração, que tem como valores mais relevantes a criatividade, imaginação e o sentido artístico. A construção desse mundo é baseada nos escritos de Santo Agostinho, em City of God. A produtividade e o valor de uso não têm importância crucial.

2-O mundo doméstico foi extraído do trabalho de Jacques Boussuet, La politique tireé des propres paroles de l'écriture sainte. Tem como referência 
a família, tradição, a proximidade e os ancestrais. Na construção política de Boussuet, o rei, que é a principal pessoa, se compara ao pai, que se sacrifica por seus objetivos (BOLTANSKI;THÉVENOT, 1999). São considerados os hábitos e as relações de fidelidade entre as pessoas. A hierarquia e as relações de confiança são os maiores valores.

3 - No mundo da opinião ou renome a grandeza depende da opinião dos outros. Este mundo tem base na obra O Leviatã, de Thomas Hobbes, particularmente o capítulo dedicado à honra (BOLTANSKI;THÉVENOT, 1999). A ordem de grandeza é a reputação, reconhecimento e sucesso.

4 - No mundo cívico, "a grandeza é a vontade coletiva, que deve prevalecer sobre a vontade individual" (DORIGON, 2008: 74). Inspirado no Contrato Social, de Rousseau, nessa esfera são ressaltados os valores de igualdade, liberdade, solidariedade e democracia, bem como preocupações com meio ambiente e bem estar social. A vontade geral é o princípio superior e mais representativo.

5 - No mundo industrial os fundamentos são o desempenho técnico e a ciência. Seus princípios foram bebidos na obra de Saint Simon, que versavam sobre o trabalho e produtividade. A empresa deve operar com equipamentos modernos, buscando a excelência. A especialização, profissionalização, norma, estratégia correta e o conceito de organização são atributos dessa natureza.

6 - O mundo mercantil valoriza os princípios que regem as leis de mercado. Adam Smith, com A riqueza das nações, é a base desse mundo, que busca pela clientela e competitividade, e onde a tônica é fechar negócios. Grande é quem vence a concorrência e possui mais riquezas materiais. O investimento é realizado de acordo com a oportunidade e com distanciamento emocional.

Neste artigo, o interesse recai especialmente nas convenções como essa teoria trata da construção social e da percepção da qualidade de produtos provenientes do campo, como é o caso do vinho.

\section{Gestão do conhecimento}

O vinho é um produto industrial diferenciado. Não pode ser concebido com a mesma intenção de quem produz sucos ou refrigerantes, por exemplo. $\mathrm{O}$ vinho fino não atende à lógica de padronização e maximização da produção, mas é o resultado da intuição, paixão e da trans- 
missão e absorção de conhecimentos tácitos e explícitos. Esse conhecimento não é previsível ou facilmente codificado, mas reside no campo da experiência e do talento individual.

Batalha (2000), estudioso do agronegócio, observa um novo pensamento no setor onde se valoriza o indivíduo e o seu conhecimento. Para ele, as empresas relacionadas ao agronegócio estão percebendo a importância do capital humano como meio de se buscar novas oportunidades de negócios e do gerenciamento das mudanças. Drucker,já em 1999, compreendia que o trabalho se tornava cada vez mais baseado no conhecimento, como, também, o papel das organizações na criação e difusão do saber. Segundo o autor, a organização pode oferecer a continuidade básica que os trabalhadores do conhecimento precisam para serem eficazes.

A economia do conhecimento desloca o eixo da riqueza e do desenvolvimento de setores industriais tradicionais - intensivos em mão de obra, matéria-prima e capital - para setores cujos produtos, processos e serviços são intensivos em tecnologia e conhecimento. Na visão de North (2010: 4), "a gestão do conhecimento tem como objetivo aproveitar de forma ótima os conhecimentos existentes, desenvolvendo e transformando-os em novos produtos, processos e campos de atividade econômica".

Nonaka e Takeushi (1997) classificam o conhecimento humano em dois tipos: tácito e explícito. Este último é o que pode ser articulado na linguagem formal, inclusive em afirmações gramaticais, expressões matemáticas, especificações, manuais etc., facilmente transmitido, sistematizado e comunicado. Esse foi o modo dominante de conhecimento na tradição filosófica ocidental. O conhecimento tácito é difícil de ser articulado na linguagem formal, pois se trata de um saber incorporado à experiência individual e envolve fatores intangíveis como crenças, perspectivas, sistema de valor, insights, intuições, emoções e habilidades.

Polanyi apud Binotto (2005) define conhecimento tácito com a frase: "we can know more than we can tell" (nós sabemos mais do que somos capazes de falar, tradução nossa). As pessoas possuem mais habilidades do que conseguem expressar pela fala, ou seja, o conhecimento vai além das possibilidades da linguagem. Trazendo a noção de conhecimento tácito e explícito de Nonaka e Takeuchi para o caso da produção dos espumantes no Brasil, existia - e ainda existe - conhecimento tácito na 
produção da bebida, baseado na experiência, desde as primeiras tentativas. Esse conhecimento, mesmo que ainda incipiente, foi se transformando em explícito, possibilitando que outros tivessem acesso.

Ampliando o olhar para fatores externos, pode-se dizer que a situação econômica do país e a política agrícola do governo exercem forte influência sobre o agronegócio. $\mathrm{O}$ contexto externo das empresas agrícolas e suas relações de interdependência serão examinados com o modelo teórico dos Capitais do Conhecimento (Cavalcanti et al, 2001), modelo teórico formulado por pesquisadores do Centro de Referência em Inteligência Empresarial (CRIE), vinculado à Universidade Federal do Rio de Janeiro (UFRJ). Os capitais do conhecimento são formados pelos capitais ambiental, estrutural, intelectual e de relacionamento. Esse paradigma nos ajudará na interpretação do cenário vinícola brasileiro.

O capital ambiental é o conjunto de fatores em que a organização está inserida, levando-se em conta suas características socioeconômicas, naturais e aspectos governamentais, culturais e financeiros, e se existem mecanismos apropriados para fomento à produção. Com esteio desse modelo, será analisado o ambiente de negócios no setor vinícola do Rio de Grande do Sul para avaliar seus pontos favoráveis e onde estão seus gargalos. Como é a taxação dos vinhos brasileiros? Qual a influência dos fatores naturais? Existe mão de obra qualificada? Existe matéria-prima de qualidade e quantidade suficientes?

O capital estrutural é o mais fácil de ser identificado e de contabilizar. É o único capital que a organização de fato possui.É o conjunto de sistemas administrativos, conceitos, modelos, rotinas, marcas, patentes e programas de computador. Nesse capital, está contido o modo como a empresa funciona, ou seja, seu modelo de gestão, processos de negócio e sua estrutura organizacional.

Há, ainda, o capital intelectual e o de relacionamento. O intelectual é aquele que o indivíduo detém e se refere às capacidades, experiências e o conhecimento formal das pessoas que integram a organização. Nesse aspecto, North também tem a contribuir, ao afirmar que:

O conhecimento não existe sem as pessoas, motivo pelo qual a gestão orientada às competências significa, sobretudo, interagir com aqueles que são portadores de saberes, em outras palavras: utilizar os potenciais do co- 
nhecimento dos companheiros de trabalho e, mais especificamente, desenvolver e facilitar o acesso aos especialistas (...) busca-se menos 'mão de obra' e mais 'mente de obra'. (NORTH, 2010: 97)

Por fim, há o capital de relacionamento, que se volta para o estabelecimento de alianças e parcerias com clientes, fornecedores, sindicatos, governo, instituições financeiras, concorrentes, meios de comunicação e outros grupos de interesse. Em um ambiente globalizado e competitivo, uma empresa isolada terá muito menos chance de progredir.

\section{Lá no passado}

Para descobrir os fatores que fizeram o espumante brasileiro melhorar de qualidade foi preciso buscar o pretérito e, só assim, avistar as diferenças no processamento da uva e do vinho desde o início do plantio de videiras no Brasil até os dias de hoje. O início da viticultura no Brasil ocorre com a chegada de imigrantes italianos ao Rio Grande do Sul, a partir de 1870. As uvas eram destinadas para consumo familiar e produção de vinhos de mesa ${ }^{3}$. Praticamente 100 anos depois, a partir da década de 1970, com a chegada de empresas multinacionais, começa-se a observar um incremento significativo no plantio de videiras viníferas no Brasil e consequente melhora na qualidade dos vinhos (ALZER; BRAGA, 2004).

A vinicultura brasileira se desenvolveu com mais vigor na região Sul, mas foi em São Vicente, vila que viria a se tornar a cidade de São Paulo, onde aconteceram as primeiras tentativas de plantio de uva e de vinificação feitas pelo português Brás Cubas nos idos de 1500. Porém, o clima litorâneo não favoreceu a cultura. (CAVALCANTE, 2010).

A cidade de Garibaldi - hoje conhecida como a capital do espumante brasileiro - nasceu em 1870 como a colônia Conde D'Eu, denominada assim em homenagem ao genro do imperador, casado com a Princesa Isabel. O povoamento da Colônia Conde D'Eu aconteceu no final da fase imperial. A partir de 1874 e 1875 começaram a chegar novas levas de imigrantes suíços, italianos, franceses, austríacos e polo-

3 Vinhos produzidos com uvas não viníferas. 
neses. No entanto, o maior número era proveniente da Itália. (CLEMENTE; UNGARETTI, 1993).

Em outubro de 1900, o governo eleva Conde D'Eu à condição de município, que passa a se chamar Garibaldi, em homenagem ao italiano Giuseppe Garibaldi, que participou da Revolução Farroupilha e é considerado "herói dos dois mundos". (BALZANI, 2007). O primeiro espumante brasileiro foi produzido em Garibaldi pela família italiana Peterlongo, em 1913 - e feito pelo método Champenoise (com segunda fermentação na garrafa) (CLEMENTE; UNGARETTI, 1993).

$O$ francês Georges Aubert também merece lugar na história do espumante brasileiro. Ele e mais três sócios resolveram abandonar a Europa, em 1950, após a II Guerra Mundial. Assim, a família Aubert transferiu a vinícola para Garibaldi, de onde passaram a elaborar o champanha, a partir de 1951.

Pode-se dizer, então, que a produção de espumantes no Brasil não é uma novidade. Como visto, desde a segunda década do século XX espumantes já eram elaborados no Rio Grande do Sul. Porém, até atingir um patamar internacional de qualidade, muitas mudanças tiveram que ocorrer na lavoura, na produção e no transporte do vinho. A produção era descuidada em várias etapas, desde o plantio, escolha da matériaprima, vinificação, engarrafamento, armazenamento e transporte.

Cabral (2007) relata como era feito o transporte das uvas e o acondicionamento do vinho durante o final do século XIX, no Rio Grande do Sul

$\mathrm{Na}$ maioria das vezes, o vinho a ser vendido era acondicionado em barriletes de 40 litros e transportados em lombo de animais até o local onde o negociante os juntava para levá-los e vendê-los nos maiores centros, como Porto Alegre, Montenegro e outras localidades" (...) Do depósito do comerciante, o transporte para os centros de consumo era feito em carroções grandes, puxado por até oito mulas. Quando o produto chegava a seu destino, era trasfegado para uma pipa de grande capacidade, devolvendo-se os barriletes de 40 litros aos produtores. Naquela época, dependia do acaso o surgimento de um vinho melhor ou pior. (CABRAL, 2007: 146) 


\section{Marcos históricos do setor vinícola brasileiro}

Para se começar a produzir vinhos tranquilos e espumantes de qualidade no Brasil foi preciso mudar a mentalidade do setor, que valorizava a quantidade em detrimento da qualidade. Alguns fatos foram divisores: a criação de centros de ensino de vinicultura a partir da década de 20; a chegada de profissionais capacitados junto com as multinacionais na década de 70; e a abertura do mercado nos anos 90.

Esses acontecimentos influenciaram o comportamento dos que se atinham a técnicas descuidadas. Os produtores foram impelidos a tratar com mais zelo a matéria-prima em todas as fases - desde a lavoura até a cantina -, como também passaram a investir em equipamentos modernos para a produção do vinho e na capacitação dos profissionais.

\section{Centros de ensino}

O setor vinícola brasileiro ainda tem perfil de indústria familiar. Em geral, ainda é um negócio que passa de pai para os filhos. Com as transformações do setor e o aumento da competitividade muitos donos de vinícolas passaram a investir em estudos para membros da família que nela trabalhavam. Os produtores foram percebendo que o conhecimento recebido de seus ancestrais, baseado apenas na tradição oral e na experiência, apesar de ter valor, não era mais suficiente para mantê-los competitivos. Resolveram investir na formação de seus quadros, como buscar profissionais fora do círculo familiar.

Hoje em dia, vinícolas de grande porte até contratam consultores para orientá-los na elaboração de determinados vinhos. Já nos idos de 30 , alguns produtores estavam se convencendo de que era preciso melhorar a qualidade do vinho produzido e começaram, mesmo que lentamente, a se organizar, formando grupos para troca de conhecimento.

Já na década de 20, começou, no Rio Grande do Sul, um processo importante para a melhora da qualidade dos vinhos: o plantio de uvas europeias, em detrimento das uvas americanas. Os produtores estavam interessados em aprender as técnicas de cultivo dessas castas, consideradas mais complexas, como também conhecer formas de elaborar vinhos com base no saber científico (CABRAL, 2007). 
Além de iniciar timidamente a mudança para castas europeias, outro desafio foi convencer os produtores a converter o sistema de plantio das videiras, trocando para o sistema de espaldeira - em vez do de latada. O sistema de espaldeira permite maior insolação dos frutos. Os agricultores eram, e ainda são, resistentes a essas transformações e preferem plantar variedades americanas, por sua resistência a pragas e adaptação ao clima da região.

Outras instituições foram surgindo para dar apoio aos vinicultores. Em 20 de outubro de 1937 foi criado o Laboratório Central de Enologia, com sede no Rio de Janeiro, e três Estações de Enologia com sedes no Rio Grande do Sul, São Paulo e Minas Gerais. Em julho de 1941 foi colocada a pedra fundamental da estação de enologia de Bento Gonçalves, iniciando suas atividades em maio do ano seguinte. Em agosto de 1975 foi criada a Unidade de Execução de Pesquisa de Âmbito Estadual (UEPAE) de Bento Gonçalves, que em março de 1985, através da Deliberação 008/85, foi denominada de Centro Nacional de Pesquisa de Uva e Vinho (CNPUV), entidade hoje conhecida como Embrapa Uva e Vinho. (Embrapa, s/data) ${ }^{4}$.

A Embrapa é de fundamental importância para o setor por viabilizar soluções de pesquisa, desenvolvimento e inovação para a sustentabilidade da vitivinicultura. A instituição realiza pesquisas sobre as cultivares mais apropriadas para a região; cria ou adapta máquinas, implementos e utensílios para a atividade agropecuária ou agroindustrial; desenvolve insumos biológicos e químicos, além de mapear e delimitar áreas (zonas ou faixas) da superficie terrestre para fins específicos e produzir programas de computador, relacionados com as atividades agropecuárias.

Outro importante centro de ensino, a Escola Agrotécnica Presidente Juscelino Kubitschek, de Bento Gonçalves, começou a funcionar em 1960 com o curso técnico em enologia. Em 1999, passou a oferecer um curso superior em enologia (CABRAL, 2007).

4 Disponível em: < http://hotsites.sct.embrapa.br/pme/historia-das-unidades/regiaosul\#uvaVinho>. Acesso em 20 set. 2012. 


\section{Chegada de multinacionais}

A modernização tecnológica da indústria vinícola brasileira começou na década de 70, com a chegada de multinacionais e profissionais bem capacitados, que perceberam o potencial do Sul do Brasil para produção de vinhos tranquilos e espumantes de boa qualidade. Essas empresas contribuíram de maneira fundamental para reestruturar o setor, interferindo essencialmente nos capitais estrutural, ambiental e de relacionamento.

A década de 1970 seria um marco em nossa indústria, pois agora o mundo passava a nos contemplar como um 'país potencial' para o vinho. Chegam as multinacionais do setor - Martini \& Rossi, Moët \& Chandon, Maison Forestier, Heublein e Almadén - e com elas tecnologia de ponta e enólogos formados nos quatro cantos do mundo. Era um novo e importante momento para a vitivinicultura do Brasil. (CABRAL, 2007: 163).

'Contaminadas' pela nova onda tecnológica e pelos modos de gestão que as multinacionais trouxeram, as empresas locais começaram, gradualmente, a se modernizar, investindo em equipamentos e desenvolvendo competências. Só assim conseguiriam, pelo menos, acompanhar a qualidade dos novos fermentados elaborados e se manterem competitivas. Houve, então, uma mudança no capital estrutural das vinícolas brasileiras. Esse capital alude tanto aos bens físicos como à forma que a organização trabalha, quer dizer, sua cultura.

A tecnologia não ajudou apenas na elaboração de vinhos tranquilos, mas também na dos espumantes. As multinacionais trouxeram know-how. Começaram a surgir entidades que ajudariam a organizar e representar o setor institucionalmente, como sindicatos, cooperativas e associações. Em 1976, por exemplo, foi fundada a Associação Brasileira de Enologia (ABE), que organiza a participação dos vinhos brasileiros em concursos e se propõe a desenvolver trabalhos visando o aperfeiçoamento dos técnicos da área de Enologia eViticultura. A União Brasileira deVitivinicultura (Uvibra) surgiu em 1967 e, até hoje, atua como entidade de classe que reúne e congrega empresas e entidades setoriais da vitivinicultura brasileira (DAL PIZZOL, 1988).

Os produtores puseram-se a formar grupos e arranjar parceiros, fortalecendo, mesmo de maneira rudimentar, o capital de relacionamen- 
to, que por sua vez, pode aumentar o capital intelectual. O capital de relacionamento compreende as alianças estratégicas estabelecidas pelas organizações, sejam elas com clientes, fornecedores, sindicatos, governo, instituições financeiras, meios de comunicação e grupos de interesse diversos. "O capital de relacionamento é definido como a rede de relações de uma organização com clientes, fornecedores e parceiros" (CAVALCANTI et al., 2001:71). Com o tempo e conhecimento os métodos seriam outros, desde a escolha das cepas, cultivo da videira e colheita dos cachos até a manipulação das uvas na cantina.

\section{Abertura do mercado}

Outro impulso significativo foi a abertura do mercado brasileiro, no início da década de 90 . O consumidor passou a ter acesso a vinhos de várias partes do mundo e começou a apurar seu gosto, fazendo comparações e tornando-se mais exigente. A indústria vinícola brasileira teve que se movimentar. A abertura do mercado também facilitou a obtenção de equipamentos importados para vinificação. $\mathrm{O}$ produtor mais consciente começou a fazer amplas mudanças no campo e também na cantina, onde os vinhos são elaborados.

O consumidor brasileiro foi ficando com o paladar mais apurado diante de opções tão variadas, e com maior interesse pelo setor: passou a querer saber mais sobre qualidade, procedências, safras e as diversidades varietais existentes. (DI GIULIO, 2007: 12)

Essa transformação embrionária do espaço comercial com a entrada de concorrentes estrangeiros esboçou uma mudança no capital ambiental e relaciona-se, ainda, com a natureza 'mercantil' da Teoria das Convenções, onde a busca pela clientela e a competitividade formam a tônica para fechar negócios. As empresas tiveram, mais uma vez, que se reinventar para se manter no mercado. A entrada do vinho importado, em especial os argentinos e chilenos, deixou em desvantagem o vinho brasileiro. $\mathrm{O}$ ambiente de negócios mudou sensivelmente em relação ao mercado consumidor, que ficaria mais atento exigente. 


\section{Produção vinícola no Brasil}

De acordo com o Instituto Brasileiro do Vinho (Ibravin $)^{5}$ a viticultura no Brasil ocupa uma área de, aproximadamente, 77 mil hectares, com vinhedos estabelecidos desde o extremo sul do país, em latitude de $30^{\circ}$ 56 ' 15"S, até regiões situadas muito próximas ao equador, em latitude de $5^{\circ} 11$ ' 15"S. Embora a produção de vinhos, suco de uva e derivados de ambos também ocorra em outras regiões, a maior concentração está no Rio Grande do Sul, onde são elaborados, anualmente, 500 milhões de litros de vinhos e mostos ${ }^{6}$ (ver quadro 1 , com dados do cadastro vinícola).

O panorama vinícola nacional traçado pelo $\operatorname{Ibravin}^{7}$ aponta que a produção de uvas no país é da ordem de 1,2 milhões de toneladas/ano. Deste volume, cerca de $45 \%$ é destinado à elaboração de vinhos, sucos e outros derivados; e 55\%, comercializado como uvas de mesa.

Do total de produtos industrializados $77 \%$ são vinhos de mesa e $9 \%$ são sucos de uva, ambos elaborados a partir de uvas de origem americana, especialmente cultivares de Vitis labrusca e Vitis bourquina. Cerca de $13 \%$, praticamente a sexta parte, são vinhos finos, elaborados com castas de Vitis vinifera. O restante dos produtos industrializados, $1 \%$ do total, são outros derivados da uva e do vinho, como conhaques, brandy, licor, vinagre, entre outros. A produção do Rio Grande do Sul também segue lógica parecida. Dos 325 milhões de litros de vinho e derivados produzidos em 2010195 milhões foram de vinhos comuns (vinhos de mesa, feitos com uvas americanas) e apenas 24 milhões de vinhos finos (com uvas europeias, denominadas viníferas).Ver quadro 2.

Essa alta produção de vinhos com uvas americanas é um contrassenso brasileiro. Não existe país que já tenha se firmado como produtor de vinho ou que pretenda sê-lo que elabore quantidades tão significativas de vinhos com castas americanas. O Brasil produz vinhos a partir de variedades americanas (vitis labrusca e vitis bourquina) e híbridas, que representam mais de $80 \%$ do volume total, evidenciando uma dualidade estrutural dessa cadeia produtiva (PROTAS, 2008).

\footnotetext{
$<$ http://www.ibravin.org.br/brasilvitivinicola.php>.

Sumo de uvas frescas que ainda não tenham passado pelo processo de fermentação.

7 Disponível em: <http://www.ibravin.com.br/brasilvitivinicola.php>. Acesso em: 14 out. 2011.
} 
O vinho brasileiro perde em credibilidade - a despeito da qualidade de vários rótulos - por deter uma produção de vinho de mesa em tão larga escala. Enquanto há uma enorme produção de uvas americanas para vinhos de garrafão, sucos e derivados, a produção de espumantes de qualidade é totalmente comercializada, como será visto mais adiante. Pressupõe-se que, se houvesse na região maior plantio de uvas de viníferas adequadas à elaboração de espumantes, essa produção seria absorvida pelo mercado. No entanto, não é simples nem barato converter vinhedos.

\section{O espumante do vale dos vinhedos}

NoVale dosVinhedos se produz boa parte dos espumantes nacionais mais expressivos e de maior tipicidade - se é que se pode afirmar que o Brasil, por não possuir tradição no setor vinícola, já elabora produtos de caráter reconhecível.

O Brasil pertence ao chamado Novo Mundo vitivinícola,juntamente com Chile, Argentina, Estados Unidos, África do Sul, Austrália e outros, cuja base de produção são variedades importadas dos tradicionais países produtores de vinhos da Europa. Esse termo não deixa de guardar um cunho ideológico de hegemonia, afinal o mundo tem a mesma idade. Como observa Albert (2006), a expressão Novo Mundo designa as colônias estabelecidas por europeus nas quais chegaram a produzir vinho, em contraposição ao termo Velho Mundo, que se refere à Europa, que já o produzia desde a antiguidade. Outra característica dos vinhos provenientes deste Novo Mundo é a base tecnológica, enquanto que no Velho Mundo valoriza-se a ideia do terroir.

Nem só de tecnologia se faz um bom espumante. Como explica Jorge Tonietto (2007), pesquisador da Embrapa, a qualidade de um produto vinícola decorre de uma junção de variantes:

Da combinação "clima x solo x variedades x saber-fazer local" é que nasce a original qualidade do espumante da Serra Gaúcha que tem, ao longo do tempo, ganhado crescente reputação no mercado nacional e reconhecimento de especialistas internacionais. (TONIETTO, 2007: 4). 
O professor Orlando Simões (2002), da Escola Superior Agrária de Coimbra, utilizando a Teoria das Convenções, defende que a incerteza em relação aos produtos agrários complexifica a ideia de qualidade.

As características particulares dos produtos alimentares, como a perecibilidade, a segurança alimentar, o seu valor organoléptico ou a carga socio-cultural que lhes está associada, complexificam a noção de qualidade para este tipo de produtos. Por outro lado, com a industrialização dos processos produtivos, a adequação dos produtos às tecnologias disponíveis e às possibilidades de uma transformação competitiva (relação qualidade/ custo) diversifica ainda mais esta noção. (...) A diversificação e intensificação produtiva tornaram mais difícil a avaliação da qualidade dos produtos alimentares, crescendo concomitantemente a incerteza nessa mesma avaliação. (SIMÕES, 2002: 8)

Os laços pessoais e a confiança remetem à natureza 'doméstica' dentro da literatura da Teoria das Convenções. O conhecimento sobre o local onde se é elaborado determinado produto e a forma de processálo podem reduzir o grau de incerteza por parte do consumidor. Para isso, é preciso haver uma ideia de qualidade socialmente construída. "Os mercados só podem funcionar com base numa definição prévia da qualidade dos produtos a serem trocados" (WILKINSON, 1999: 71).

Niederle (2011) defende que a qualidade associada à origem de um alimento "não é reduzida às suas características fisicas, decorrentes do fato da produção ter ocorrido segundo condições edafoclimáticas peculiares. São atributos naturais, sociais, culturais e econômicos do território, atuando através de imagens socialmente construídas, que tornam a identidade do produto reconhecível (immaterialising of food)" (NIEDERLE, 2011: 71).

OVale dos Vinhedos está localizado no Nordeste do Rio Grande do Sul, na Serra Gaúcha, entre os municípios de Bento Gonçalves, Garibaldi e Monte Belo do Sul. Está em uma zona de clima temperado, situada no paralelo $30^{\circ} \mathrm{S}$, e foi a primeira região do Brasil a receber o registro de Denominação de Origem (DO) em setembro de 2012, e também a obter uma Indicação de Procedência (IP), em 2002. A DO é uma evolução da IP, com regras que normatizam desde o plantio das uvas, passando pelo processo de elaboração, até a comercialização dos vinhos. 
O pedido para obtenção da DO foi feito pela Associação dos Produtores de Vinhos Finos do Vale dos Vinhedos (Aprovale) em 2010 e aprovado pelo Instituto Nacional de Propriedade Industrial (INPI) em 11 de setembro de 2012. A DO é a modalidade mais complexa de uma Indicação Geográfica (IG). (Aprovale) $)^{8}$.

Em 2010, o INPI também deu parecer favorável à concessão da Indicação de Procedência aos vinhos finos e espumantes da região de Pinto Bandeira, finalizando um processo que começou em 2003e demonstrando que a região tem enorme potencial vinícola. Pinto Bandeira é um distrito pertencente ao município de Bento Gonçalves, na Serra Gaúcha. (Embrapa Uva e Vinho) ${ }^{9}$.

Vinhos comuns, feitos com uvas americanas, normalmente não passam por avaliação para obtenção de denominação de origem ou indicação de procedência. (Holanda, 2012). Porém, em Santa Catarina, em 2011, o vinho da uva Goethe (cultivar americana) da região de Urussanga, recebeu o registro IP (Indicação de Procedência), tornando-se a primeira Indicação Geográfica do estado de Santa Catarina. (Fonte: Produtores de uva Goethe - ProGoethe ${ }^{10}$.

As indicações geográficas, por conterem definições legais para produção e comercialização, se afinam com a natureza 'cívica' da Teoria das Convenções. Na convenção cívica, os atores aderem a um corpo de princípios e valores públicos, como a defesa de uma região, de uma tradição, uma cultura, um patrimônio. Isso, de certa forma, reforça ainda mais a natureza 'doméstica', por aumentar o grau de confiança nesses produtos e estabelecer regularidade nas transações.

A época da colheita é um dos períodos mais delicados no cultivo de uvas com vistas à produção tanto de vinhos tranquilos como de espumantes. Porém, são requeridas diferentes características da uva para cada tipo vinho. Quanto às condições favoráveis para a produção de espumante no Sul do Brasil, tem-se que:

Via de regra, nas regiões Sul e Sudeste brasileiras, onde o ciclo da videira ocorre uma só vez por ano e é determinado fundamentalmente pelas

$8<$ http://www.valedosvinhedos.com.br/vale/viewdestaque.php? view $=275 \& \mathrm{cnid}=1$ \#null> - acesso em setembro de 2012. Na página, podem ser vistas ainda as normas vigentes para a DO.

$9<$ http://www.cnpuv.embrapa.br/tecnologias/ig/pintobandeira.html>.

$10<$ http://www.progoethe.com.br/igp.html>. 
temperaturas ambientais, o período de maturação coincide com o período chuvoso, afetando o acúmulo de açúcares, a redução dos ácidos orgânicos e a maturação fenólica da uva, originando assim vinhos pouco encorpados, de pouca expressão varietal e com poucas condições de envelhecimento. Estas condições, entretanto, não impedem a produção de espumantes de qualidade, uma vez que a maturação da película das bagas não é indispensável no processo de elaboração desses vinhos, e o equilíbrio entre açúcares e ácidos das uvas, com menor índice de maturação, é favorável à apreciação sensorial dos mesmos (REGINA et al., 2010).

As Indicações Geográficas reforçam o conceito de terroir. No entanto, no Vale dos Vinhedos, a tecnologia também está bem presente. Em geral, as instalações das vinícolas da Serra Gaúcha contam com equipamentos de última geração para elaboração, filtragem e engarrafamento de vinhos, como também boa estrutura para armazenamento e guarda das garrafas.

Roese (2008) também entende que a inovação na produção vinícola da região não rompeu, contudo, com a tradição da indústria vinícola de base familiar; pelo contrário, ela foi instrumento de preservação da gestão familiar das empresas e da manutenção de famílias unidas em torno da atividade que as caracterizou desde a chegada da primeira geração à região, no século XIX. A relação entre inovação e tradição é a de pares que se complementam e alimentam a mobilização dos esforços dos agentes econômicos locais.

Isso ocorre porque a produção do vinho no Vale dos Vinhedos está intimamente vinculada ao cultivo das tradições familiares associadas à sua origem italiana. Mesmo frente às modernizações na vinicultura, as raízes do imigrante italiano estão presentes na configuração do espaço em que o vinho é produzido. A inovação ocorreu com a transformação no processo de fabricação do vinho, a partir da incorporação de máquinas e de recursos humanos qualificados, na reconfiguração da divisão do trabalho na cadeia produtiva do vinho e na mudança no conceito do que é um bom vinho (ROESE, 2008: 80).

Uma Indicação de Procedência dá a entender ao consumidor que o produto possui qualidade por suas características intrínsecas e regionais, ou por seu processo de concepção, produção e comercialização. A incerteza é reduzida e confinada à variação possível dentro da categoria 
da Indicação de Procedência (SIMÕES, 2002).As Indicações Geográficas são tradicionais no mundo do vinho. A própria região de Champagne (França) é uma, além de Rioja (Espanha), Chianti (Itália), Porto (Portugal), entre tantas outras. Como afirma Tonietto (2002), desde a Antiguidade a produção de vinhos utiliza o nome geográfico das zonas de produção como sinal de qualidade para vinhos de maior reputação.

\section{Consumo interno de espumante}

O mercado interno demonstra animação em relação ao espumante, consumindo praticamente toda produção, como infere a pesquisadora da Embrapa Loiva Mello. Segundo dados do Ibravin ${ }^{11}$, de 2004 a 2009 o consumo de espumantes (brut e moscatel) dobrou, saltando de 5,48 milhões de litros para 11,20 milhões. De janeiro a outubro de 2010 foram colocados 7,9 milhões de litros de espumantes nas taças dos brasileiros, um acréscimo de $21 \%$ em relação ao mesmo período de 2009. Ainda, de acordo com o Ibravin, o mercado de espumantes está em crescimento contínuo desde 2002. O aumento alcança uma taxa de 12,5\% ao ano.

O cenário para o espumante brasileiro é promissor. Atentas ao mercado, vinícolas de grande porte da Serra Gaúcha aumentam a produção de espumante na ordem de $15 \%$ a $25 \%$ ano após ano (Ibravin). A comercialização da bebida e a organização da indústria apontam para duas dimensões conceituadas na Teoria das Convenções: a mercantil e a industrial. Na natureza mercantil, a qualidade resulta do funcionamento do mercado, quando os atores avaliam diretamente o produto durante as transações. A relação das pessoas é estabelecida pela concorrência e sua relação com os objetos é determinada pelo lucro (SIMÕES, 2002).

Praticamente toda produção de espumante é consumida pelo mercado interno. Por outro lado, existe uma superprodução de uvas americanas para consumo in natura, sucos e vinhos de mesa. Segundo o levantamento feito pelo Uniad (2007), há diferenças estatísticas para vinho e destilados entre as preferências de homens e mulheres. A pesquisa detalha os tipos de destilados consumidos (uísque, cachaça, rum, vodca e conhaque), mas não entra em detalhes sobre os tipos de vinho (tran-

11 <http://www.ibravin.org.br/admin/UPLarquivos/160520121104262.pdf>. 
quilos ou espumantes, finos ou de mesa, tintos ou brancos). Mesmo assim, nos dá pistas sobre o consumo específico de vinho espumante.

O estudo aponta que 34\% das mulheres preferem beber vinho, enquanto que os homens apresentaram um percentual de 19\%. Em relação aos destilados, os homens apresentaram $17 \%$ de preferência, e as mulheres, $6 \%$. O consumo de cerveja (quase dois terços do total consumido, variando de $58 \%$ a $62 \%$ ) e bebidas "ice" (responsáveis ainda por pequeno consumo, $2 \%$ ) não apresentaram diferenças no consumo entre os gêneros (Uniad, 2007: 38).

O estudo também expõe diferenças de consumo por região e por classe socioeconômica. $\mathrm{O}$ consumo de vinho seria maior na região Sul $(29 \%)$ e Sudeste (27\%). As classes socioeconômicas foram divididas em A, B, C, D e E. Em todos os níveis, o consumo de vinho é considerável: $38 \%, 27 \%, 25 \%, 24 \%$ e 18\%, respectivamente (Uniad, 2007: 39). Podemos supor que o consumo de vinho é possível e significativo em todas as classes porque o Brasil produz vinhos de qualidade e preços muito distintos. Como vimos, o vinho de mesa representa mais de $70 \%$ da produção nacional.

Roese (2008) faz uma análise ampla sobre a questão das mudanças em relação ao consumo de vinho:

A expansão da oferta de vinho e a ampliação dos segmentos sociais que tem acesso ao seu consumo vêm modificando o panorama da produção e do consumo, o que inclui mudanças no gosto do consumidor e na percepção que os produtores têm da influência desse gosto na produção do vinho. Sendo assim, a transformação do mercado do vinho e sua globalização tornam mais complexa a relação entre a produção e a demanda, sobretudo por tratar-se de um ramo em que o gosto do consumidor é o "calcanhar de Aquiles" do produto e objeto de disputa entre os próprios produtores e entre estes e os "formadores de opinião" do meio (ROESE, 2008: 74).

Dos cerca de 400 milhões de litros de vinho produzidos no país apenas 12 milhões são de espumantes, o que demonstra que o produto possui potencial para crescimento, dada a aceitação dos consumidores. A relativa escassez de matéria-prima e a concorrência na região causam tensão no relacionamento do produtor de uva com o produtor de vinho fino. $\mathrm{O}$ agricultor tem que trabalhar de acordo com o programa da vinícola. São os engenheiros agrônomos, sob a orientação dos enólogos 
das vinícolas, que definem quando plantar e colher, quais defensivos agrícolas usar, que tipo de condução e qual o grau de açúcar desejado. Há muita especulação. $\mathrm{Na}$ época da vindima, dependendo da qualidade da safra, algumas vinícolas costumam 'cobrir' a oferta do concorrente para com o produtor de uva para garantir a produção de seus vinhos, sejam tranquilos ou espumantes.

Alguns rótulos do vinho tranquilo nacional começam a ser reconhecidos, mas, por hora, é o espumante quem encabeça a preferência do mercado interno e a lista de premiações em concursos internacionais. A mídia também não deve ser esquecida quando se trata de influenciar opiniões. Existem fartas reportagens laudatórias sobre o espumante brasileiro, especialmente quando algum produto é premiado em concursos internacionais.

A opinião dos críticos especializados e a ampla divulgação dos seus pareceres e das notas atribuídas aos vinhos, cumprem um duplo papel: o de formar opinião entre os consumidores e o de criar uma referência pública para os produtores que vêem seus vinhos serem comparados aos concorrentes e obterem notas maiores ou menores. Os críticos mais prestigiados e, por isso mesmo, mais influentes, acabam fazendo o papel do que, em administração, chama-se de benchmarking, que nada mais é do que a criação de espaços em que as empresas possam comparar seu desempenho com as ditas empresas mais competitivas (ROESE, 2008: 76).

O papel da imprensa e da divulgação é previsto na cidade de renome na literatura das Convenções. Neste mundo, o que é visto como relevante são a fama, as personalidades, estrelas, líderes, jornalistas:

Eles são grandes quando são famosos, reconhecidos e convincentes. Os objetos válidos neste mundo são marcas, emblemas, transmissores e receptores de mensagens, comunicados de imprensa e folhetos. A maneira correta de fazer relações é, então, influenciar, se identificar com alguém, ou apelar para que alguém emita rumores. (BOLTANSKI;THÉVENOT, 1999).

No entanto, o entusiasmo em relação ao espumante brasileiro pode levar a crer que todos os produtos são de boa qualidade. Há muita informação e confusão a respeito. $\mathrm{O}$ vinho em geral possui uma mística para além de suas variáveis palpáveis. Seu consumo confere 'distinção', 
pois se supõe que exige do consumidor, além do dinheiro para a aquisição, certo conhecimento.

O consumo massificado de "bens de luxo"é um fenômeno bem recente no mercado mundial e está associado a um relativo aumento da capacidade de consumo da classe média e ao crescimento da oferta global de produtos que antes eram destinados exclusivamente ao consumidor de altíssima renda.A massificação do luxo tem como reflexo o surgimento de empresas detentoras de marcas de produtos que tem seu nome associado à exclusividade, tradição, alta qualidade e luxo. Para ter-se uma idéia, uma mesma empresa controla e distribui as marcas Veuve Clicquot e Chandon (champanhes), Louis Vuitton (bolsas), Montblanc (canetas, jóias), entre outras (ROESE, 2008: 75).

Para Tonietto (2007), o espumante de terroir da Serra Gaúcha corre o risco de ter sua imagem comprometida ao longo do tempo, com perda de identidade, qualidade e originalidade, por conta da competição com outros espumantes que não expressam o terroir da Serra Gaúcha e que possuem menor qualidade e preço. A noção de qualidade é difícil de apreender no nível sensorial pelo consumidor, requerendo a intermediação de normas e métodos de avaliação, os quais, por sua vez, estão incorporados em instrumentos ou "coisas" que representam esses valores.

A qualificação de produtos, por sua vez, pressupõe a qualificação do trabalho e das organizações envolvidas em sua produção. Esse processo recíproco está em forte contraste com a ideia neoclássica de transparência e auto-suficiência do produto, onde o mecanismo de preços incorpora toda a informação requerida. Aqui, ao contrário, a qualidade do produto é interpretada à luz de uma avaliação dos produtores e organizações que subscrevem o produto. Tal controle de qualidade numa 'economia da qualidade'é assegurado preferencialmente pela consolidação de redes e pelo desenvolvimento de relacionamentos baseados em confiança (WILKINSON, 1999: 71-72).

A confiança pertence ao mundo doméstico, dentro da Teoria das Convenções. A criação de IGs se relaciona diretamente com a ideia de se ajustar procedimentos e matérias-primas que traduzam as características de determinados produtos. 


\section{Alta tributação x competitividade}

Dentro do escopo do capital ambiental estão os aspectos financeiros, como a tributação, taxa de juros, e a existência de mecanismos adequados para estimular a produção. Mira-se, nessa parte, a tributação operada no setor. A sobrecarga de taxas aplicadas desde a produção do vinho até sua distribuição torna o produto brasileiro ainda pouco competitivo frente a muitos importados provenientes de países da América do Sul e Europa.

Um estudo realizado em 2005, por Kelly Lissandra Bruch e Jaime Evaldo Fensterseifer, indica que a média da tributação incidente sobre a garrafa de vinho é de $45 \%$, variando de $36 \%$ a $56 \%$. Os pesquisadores analisaram a tributação sobre os vinhos finos, de mesa e espumantes com base na compreensão do sistema tributário brasileiro, buscando verificar quais são os tributos incidentes nessa cadeia e sua porcentagem no preço de uma garrafa de vinho oferecida ao consumidor final.

Os autores afirmam que se trata de uma carga tributária elevada, comparativamente a dos principais países produtores de vinho da América do Sul, com sérias implicações para a competitividade da cadeia vitivinícola brasileira. (BRUCH, FENSTERSEIFER, 2005). Há uma infinidade de impostos que incidem sobre as vendas (ICMS, IPI, PIS E COFINS, ISSQN, FUNRURAL, CPMF ${ }^{12}$ ); sobre custos e despesas (INSS empregado, INSS trabalhador, SESI, SENAI, SENAC, SESC, SEBRAE, SAT e salário-educação) e sobre o lucro (IR e CSLL). Os elos considerados pelos autores para a incidência da tributação foram: produtor rural, indústria, distribuidor e varejo.

Um ponto especialmente negativo para os produtores do Sul é a diferença do valor do ICMS que se paga em cada estado. Enquanto no Rio Grande do Sul a alíquota é de $17 \%$, a média dos estados é de $25 \%$, chegando a $27 \%$ e a $30 \%$ em alguns. De acordo com Bruch e Fensterseifer (2005), tal diferença inibe a venda de vinhos do Rio Grande do Sul para outros estados, diminui a produção e venda de vinho nos demais estados, auxilia na prática da elisão fiscal e faz o vinho brasileiro perder competitividade frente aos importados. A alíquota nacional média de

12 Esse imposto foi extinto em 2007. O estudo foi realizado em 2005, antes da extinção. Por isso, o tributo foi considerado no cálculo. 
ICMS é 25\%. No Chile, a alíquota do imposto semelhante é de 19\% e na Argentina é de 21\%. Outros tributos que encarecem sobremaneira o vinho no Brasil são o PIS e o COFINS que, calculados conforme o lucro real, somam 9,25\% do valor final do vinho. Não há, na Argentina e no Chile, tributo semelhante, confirmando que o Brasil não é nada amigável quando se fala em impostos, prejudicando o ambiente de negócios.

\section{Considerações finais}

O vinho do Brasil ainda está associado a status, à coisa de conhecedor. Já em tempos anteriores à pesquisa in loco, percebeu-se que as fontes bibliográficas disponíveis não seriam suficientes para, sozinhas, levar a conclusões. Além das visitas de campo, seria preciso conversar com pessoas-chave do setor. São as redes que nos levam a outras fontes e ideias, de forma viva e dinâmica.Aos excessivamente cerebrais, dizemos que intuição também faz parte.

Se o país produz espumantes desde o início do século XX, o que aconteceu para que esses produtos passassem a ser reconhecidos agora? O Brasil não tem tradição vinícola, algo que só se conquista com séculos de boa produção. $\mathrm{O}$ vinho fino é um produto-arte, não um produto-fórmula, se é que se pode conceituar dessa maneira. De nada adianta ter condições ambientais favoráveis sem que se saiba compor com elas. Há uma íntima relação entre a região (e suas peculiaridades de solo e clima), as uvas, procedimentos e profissionais envolvidos com o produto gerado. OVale dos Vinhedos possui clima apropriado para a produção de uvas visando a elaboração de espumantes. Mas, no passado, faltavam procedimentos adequados e conhecimento para plantio e cultivo de videiras que se adaptassem a essas condições.

A pesquisa bibliográfica e de campo permitiu elencar três fases importantes da indústria vinícola brasileira: a primeira refere-se à criação dos centros de formação e pesquisa em enologia antes da metade do século XX; depois, a chegada das multinacionais nos anos 70 e a abertura do mercado na década de 90. Esses acontecimentos implicaram tanto mudanças no campo - desde o cultivo das uvas até seu transporte - como também na cantina, que teve que se modernizar com novos 
equipamentos e adequar sua linha de produção. Simultaneamente, os profissionais que atuam nas várias etapas da elaboração do vinho foram se capacitando formalmente, sem ficarem dependentes exclusivamente do conhecimento que foi passado pelos ancestrais, embora esse saber também tenha valor.

Há um melhor aproveitamento das condições climáticas da região. Os produtores têm informação sobre as castas a serem cultivadas, considerando as características de determinado solo e clima, o que preserva a tipicidade da uva e, consequentemente, do vinho.

No entanto, houve pouca evolução no meio rural. A primeira ponta da cadeia, o agricultor, continua mal preparado e mal remunerado, o que acaba gerando dificuldades em outros anéis da indústria vinícola. O espumante deve ser elaborado com uva vinífera, que exige mais custos para cultivo e cuidados específicos, além de ter produtividade reduzida e ser conduzida preferencialmente em sistema de espaldeira. Porém, o produtor se desinteressa em seu cultivo por não ser gratificado à altura de seu trabalho e dos riscos que corre, por conta do clima e das pragas. Preferível manter a lavoura de uvas americanas, que atende ao mercado de vinhos de mesa, sucos e do consumo in natura. Mesmo remunerando menos, a uva americana é mais simples de ser cultivada, o que, na conta final, compensa o agricultor.

Como visto nesta pesquisa, a maior parte da produção é de uvas americanas. Mudar a lavoura para o plantio de uvas viníferas requer tempo e dinheiro. Além disso, as uvas americanas atendem ao mercado de sucos, geleias, entre outros produtos, e ao consumo in natura. As videiras demoram em média cinco anos para sua primeira safra, isso se não houver erros nos fundamentos básicos. Como escape, grandes vinícolas investem em propriedades fora do Vale dos Vinhedos - visto que neste território não há mais terras para aquisição, além do preço ser muito alto - para obter matéria-prima para elaboração de seus vinhos. Porém, uvas provenientes de outras regiões possuem características diferentes, o que pode embaraçar a criação de novas Indicações Geográficas.

Esse problema reflete uma política setorial ainda frouxa, que não prevê um planejamento integral, partindo do campo ao mercado. $\mathrm{O}$ fortalecimento da indústria vinícola brasileira deve passar pelo cuidado no setor agrícola, especialmente com a figura do agricultor. Não se pode 
considerar apenas a dimensão do mercado ou o produtor de vinho. Existem dinâmicas e interesses conflituosos entre agricultores, produtores de vinho e as esferas governamentais. $\mathrm{O}$ agricultor tem que se sentir estimulado a produzir uvas de qualidade e quantidade necessárias, evitando que a matéria-prima venha, forçosamente, de outras regiões. A assimetria de poder entre os atores envolvidos na indústria poderia ser minimizada com garantias mínimas para o lado mais fraco.

Outro ponto de reflexão recai sobre a carga tributária. Não é razoável que, em uma garrafa de vinho, a metade de seu preço seja de impostos. A sobrecarga de taxas aplicadas desde a produção do vinho até sua distribuição prejudica o desempenho do fermentado brasileiro, que ainda é pouco competitivo frente a muitos importados provenientes de países da América de Sul e Europa. O espumante brasileiro, no entanto, mesmo taxado igualmente consegue ser competitivo frente aos importados. O consumo triplicou de 2000 a 2010, enfrentando a concorrência do prosecco italiano, do cava espanhol, de espumantes argentinos e champagnes. A boa perfomance do espumante brasileiro pode ser atribuída à qualidade constante e à possibilidade de competir com similares aos importados, em várias faixas de preço.

A Embrapa, com seu trabalho de pesquisa, é fundamental para o direcionamento do setor. O Ibravin, com a função de divulgação e coordenação, também contribui para a evolução do vinho brasileiro, embora exista uma carência de ações em nível nacional. Ações que envolvem indústrias só se consolidam com a articulação do governo, entidades representativas dos vários profissionais e também da sociedade. Consolidar a produção do espumante brasileiro pode fazer o país figurar como um dos protagonistas de uma indústria de alto valor agregado, o que já valida o empenho.

\section{Referências bibliográficas}

ALBERT, Aguinaldo Záckia. Borbulhas: tudo sobre champagnes e espumantes. São Paulo: Ed. Senac. 2008.

O admirável novo mundo do vinho e as regiões emergentes. $3^{\mathrm{a}}$ ed. revista e atualizada. São Paulo: Editora Senac, 2006.

ASSOCIAÇÃO BRASILEIRA DE ENOLOGIA. Disponível em: http://www.enologia.org.br/.Acesso em: 20.11.2011. 
BATALHA, M. O. Recursos humanos para o agronegócio brasileiro. Brasília: CNPq, 2000.

BOLTANSKI, L.; THÉVENOT, L. De la justification: les économies de la grandeur. Paris: Gallimard, 1991.

.The Sociology of critical capacity. In: European Journal of Social Theory. SAGE Publications, 1999.

BRAGA, Danio; ALZER, Celio. Tradição, conhecimento e prática dos vinhos. $8^{\mathrm{a}} \mathrm{ed}$. Rio de Janeiro: Jose Olympio editora, 2004.

BRASIL. Lei n 9.279, de 14 de maio de 1996. Regula direitos e obrigações relativos à propriedade industrial. Disponível em: <http://www.planalto.gov.br/ccivil_03/ leis/L9279.htm>. Acesso em: 20 jul. 2011.

BRUCH, Kelly Lissandra; FENSTERSEIFER, Jaime Evaldo. XLIII Congresso da Sober: Instituições, Eficiência, Gestão e Contratos no Sistema Agroindustrial. Ribeirão Preto, 24 a 27 de Julho de 2005. Sociedade Brasileira de Economia e Sociologia Rural, 2005.

CABRAL, Carlos. 2007. Presença do vinho no Brasil: um pouco de história. $2^{a}$ ed. São Paulo: Editora de Cultura.

CAVALCANTE, Carolina Miranda. 2010. A vitivinicultura no Vale do São Francisco: evolução institucional no sertão nordestino. Tese (Doutorado em Economia) - Faculdade de Economia, Universidade Federal Fluminense, Niterói, 2010.

CAVALCANTI, Marcos; GOMES, Elisabeth. Inteligência empresarial: um novo modelo de gestão para a nova economia. Revista Produção, v. 10, n. 2: 53-64, maio, 2001.

CLEMENTE, Elvo; UNGARETTI, Maura. A história de Garibaldi. Porto Alegre: PUCRS, 1993.

DAL PIZZOL, Rinaldo. A história da uva e do vinho no Rio Grande do Sul I. Revista do Vinho, Bento Gonçalves, v. 4, n. 1:30-26, jan./fev., 1988.

DIAS, Joana Filipa Dias Vilão da Rocha. 2005. 145f. A construção institucional da qualidade em produtos tradicionais. Dissertação (Mestrado em Desenvolvimento, Agricultura e Sociedade, área de concentração em Estudos Internacionais) - Instituto de Ciências Humanas e Sociais. Universidade Federal Rural do Rio de Janeiro. Rio de Janeiro, 2005.

DI GIULIO, Gabriela. Pesquisa e inovação: Brasil prepara-se para conquistar o mercado. In: Inovação Uniemp, Campinas, v. 3, n. 4, ago. 2007. Disponível em: < http://inovacao.scielo.br/scielo.php?script=sci_arttext\&pid=S1808-23942007000400008\&1 $\mathrm{ng}=\mathrm{pt} \& \mathrm{nrm}=$ iso $>$. Acesso em: 06 abr. 2010.

DORIGON, Clovis. 2008. 437f. Mercados de produtos coloniais da Região Oeste de Santa Catarina: em construção. Tese (Doutorado em Engenharia de Produção) - COPPE, Universidade Federal do Rio de Janeiro, Rio de Janeiro, 2008.

DRUCKER, P. Desafios gerenciais para o século XXI. São Paulo: Pioneira, 1999.

HOLANDA, Claudia Maria de. 2012. O espumante na indústria vinícola brasileira: Análise de sua evolução articulada com as teorias das convenções e dos capitais do conhecimento. Dissertação mestrado - Rio de Janeiro: COPPE, Universidade Federal do Rio de Janeiro, 2012. 
MIELE, Marcelo et al. 2007. Segments of competition in south brazilian wineries. Sci. agric. (Piracicaba, Braz.), Piracicaba, v. 64, n. 3, June 2007. Available from $<$ http://www.scielo.br/scielo.php?script=sci_arttext\&pid=S0103-901620070003 00003\&lng=en\&nrm=iso $>$. access on 06 June 2012. $<$ http://dx.doi.org/10.1590/ S0103-90162007000300003>.

MIELE, M. Análise do Cadastro Vinícola do Rio Grande do Sul para um processo inicial de caracterização do sistema agroindustrial vitivinícola gaúcho. In: CONGRESSO BRASILEIRO DE ECONOMIA E SOCIOLOGIA RURAL, 42. Cuiabá, 2004. Dinâmicas setoriais e desenvolvimento regional: anais. Cuiabá: Sociedade Brasileira de Economia e Sociologia Rural, 2004: 1-14.

NIEDERLE, Paulo André. Compromissos para a qualidade: projetos de indicação geográfica para vinhos no Brasil e na França. 2011, 263f. Tese (Doutorado em Ciências Sociais) - Instituto de Ciências Humanas e Sociais, Universidade Federal Rural do Rio de Janeiro, Rio de Janeiro. 2011.

NORTH, Klaus. Gestão do conhecimento: um guia prático rumo à empresa inteligente. Rio de Janeiro: Qualitymark. 2010.

NONAKA, I.; TAKEUCHI, H. A criação de conhecimento na empresa. Rio de Janeiro: Campus, 1997.

PROTAS, José Fernando da Silva. A produção de vinhos finos: um flash do desafio brasileiro. In: Agropecuária Catarinense. v. 21, n.1, mar., 2008.

REGINA, Murillo de Albuquerque et al. Influência da altitude na qualidade das uvas 'Chardonnay' e 'Pinot Noir' em Minas Gerais. Rev. Bras. Frutic. [online]. v. 32, n. 1: 143-150. Epub Feb 26, 2010. ISSN 0100-2945. Disponível em: <http://dx.doi. org/10.1590/S0100-29452010005000023 >. Acesso em: 20 out. 2010.

RÉVILLION, Jean Phillippe Palma et al. Qualidade sensorial de vinhos tintos finos do Rio Grande do Sul comparados aos importados da Argentina e Chile. In: Ciênc. Tecnol.Aliment. Campinas. v. 27, n. 1: 177-180, jan./mar., 2007.

ROESE, Mauro. O mondovino de cabeça para baixo: as transformações no mercado internacional do vinho e o novo empresariado vinícola. Rev. Sociol. Polit. Curitiba, v. 16, n. 31, nov. 2008.

SIMÕES, Orlando. A construção social da qualidade nos produtos agrícolas: o caso do vinho. In: La multifuncionalidad de los espacios rurales de la Península Ibérica: actas del IV Coloquio Hispano-Portugués de Estudios Rurales. Santiago de Compostela, 2002.

TONIETTO, Jorge. Pinto Bandeira no caminho da Indicação Geográfica de Vinhos. Bon Vivant, Flores da Cunha, v. 8, n. 99: 21, maio, 2007.

TONIETTO, Jorge. Indicação geográficaVale dosVinhedos: sinal de qualidade inovador na produção de vinhos brasileiros. In:V SIMPÓSIO LATINO-AMERICANO SOBRE INVESTIGAÇÃO E EXTENSÃO EM PESQUISA AGROPECUÁRIA/V ENCONTRO DA SOCIEDADE BRASILEIRA DE SISTEMAS DE PRODUÇÃO, Florianópolis, Anais. Florianópolis: IESA/SBSP: 1-16, 2002.

UNIAD. (2007). I Levantamento Nacional sobre os padrões de consumo de álcool na população brasileira /Elaboração, redação e organização: Ronaldo 
Laranjeira...[et al.]; Revisão técnica científica: Paulina do Carmo Arruda Vieira Duarte. Brasília: Secretaria Nacional Antidrogas, 2007. Brasília. <www.obid. senad.gov.br> / <www.senad.gov.br>

WILKINSON, John. Ensaios Fundação de Economia e Estatística, Porto Alegre, v. 20, n. 2: 64-80. 1999.

.A new paradigma for a economic analysis? In: Economy and Society. Routledge, v. 26, n.3, August, 1997.

36 | Marcos do Couto Bezerra Cavalcanti - Claudia Maria de Holanda 